Jurnal Ilmiah Matematika Realistik (JI-MR)

Vol. 1, No. 2, Desember 2020, 23-27

E-ISSN: 2723-6153

Tersedia: http://jim.teknokrat.ac.id/index.php/pendidikanmatematika/index

\title{
EUCLIDEAN VOICE: APLIKASI PEMBELAJARAN GEOMETRI EUCLID BERBASIS ANDROID UNTUK PENYANDANG TUNANETRA
}

\author{
Livia Agna Putri ${ }^{1}$ \\ Universitas Teknokrat Indonesia ${ }^{l}$ \\ Liviaagna@gmail.com
}

\begin{abstract}
Received: 19 November 2020
Accepted: 26 November 2020

Abstract

Based on Law number 20 of 2003, education is the right of all Indonesian citizens, including persons with disabilities, especially in this article are blind people. There should be no difference in ability between normal students and blind students to be able to learn a science, including mathematics. One of the fundamental differences is only in terms of the use of media that can help blind people as students enjoy the beauty of science in mathematics. This article discusses the development of student-based learning media for visually impaired students which is packaged in the Android application so that its use is more flexible and easier to disseminate in the future. The media is called the Euclidean Voice. The method used in this study is a literature review by analyzing relevant references using a synthesis matrix. The results of the review show that the Euclidean Voice application will be effective in its use and can be optimal to improve student understanding of Geometry Euclid material and will get a positive response from users so that users can be interested in learning advanced mathematics.
\end{abstract}

Published : 26 Desember 2020

Keywords: Android Application, Euclidean Geometry, Visually Impaired)

\begin{abstract}
Abstrak
Berdasarkan UU nomor 20 tahun 2003 sejatinya pendidikan merupakan hak dari seluruh warga negara Indonesia tidak terkecuali penyandang disabilitas, khususnya pada artikel ini adalah penyandang tunanetra. Seharusnya tidak ada perbedaan kemampuan antara siswa normal dan siswa tunanetra untuk dapat mempelajari suatu ilmu pengetahuan, termasuk matematika. Salah satu perbedaan mendasar hanyalah dari sisi penggunaan media yang dapat membantu penyandang tunanetra selayaknya siswa normal dalam menikmati indahnya ilmu pengetahuan dalam matematika. Artikel ini membahas tentang pengembangan media pembelajaran untuk siswa tunanetra berbasis suara yang dikemas pada apliaksi android agar penggunaannya dapat lebih fleksibel dan mudah untuk disebarluaskan kedepannya. Media tersebut dinamakan Euclidean Voice. Metode yang digunakan pada penelitian ini yaitu literature review dengan cara menganalisa referensi yang relevan dengan menggunakan bantuan matriks sintesis. Adapun hasil reviu menunjukan bahwa aplikasi Euclidean Voice ini efektif dalam penggunaannya serta dapat optimal untuk dapat meningkatkan pemahaman siswa pada materi Geometri Euclid dan akan mendapatkan respon positif dari pengguna sehingga pengguna dapat tertarik belajar matematika tingkat lanjut.
\end{abstract}

Kata Kunci: Aplikasi Android, Geometri Euclid, Tunanetra

Sitasi artikel ini:

Putri, L.A. (2020). Euclidean Voice: Aplikasi Pembelajaran Geometri Euclid Berbasis Android untuk Penyandang Tunanetra. Jurnal Ilmiah Matematika Realistik, 1(2), 23-27

\section{PENDAHULUAN}

Pendidikan menurut Undang-Undang No. 20 Tahun 2003 tentang Sistem Pendidikan Nasional (Sisdiknas) adalah usaha sadar, terencana, sistematis, dan berlangsung terus menerus dalam suatu proses pembelajaran untuk mengembangkan segenap potensi manusia baik jasmani maupun rohani dalam tingkatan kognitif, afektif, dan psikomotorik. Pendidikan merupakan hak semua warga negara, tidak hanya untuk sekolah dasar dan menengah melainkan sekolah dengan jenjang yang lebih tinggi. Negara memiliki kewajiban untuk 
memberi pendidikan dan memenuhi keperluan pendidikan baik dari sarana dan prasarana, hal tersebut tertuang dalam Pasal 31 ayat (1) dan Undang-Undang No. 20 Tahun 2003 tentang Sistem Pendidikan Nasional bahwa semua warga Indonesia mempunyai hak untuk mendapatkan pendidikan serta sarana dan prasarana yang memenuhi keperluan pendidikan sesuai dengan pertumbuhan dan perkembangan potensi fisik, kecerdasan intelektual, sosial, ekonomi, dan kejiwaan peserta didik disediakan oleh setiap satuan pendidikan (Admin, 2002). Pendidikan yang dimaksud tersebut tidak hanya diperuntukkan untuk orang normal saja melainkan juga yang memiliki kebutuhan khusus atau penyandang disabilitas.

Salah satu jenis anak berkebutuhan khusus adalah penyandang tunanetra. Menurut Kamus Besar Bahasa Indonesia (KBBI), tunanetra berarti tidak dapat melihat, buta. Hal ini dapat dikatakan penyandang tunanetra yaitu seseorang yang memiliki gangguan atau hambatan dalam indra penglihatan. Anak yang memiliki gangguan penglihatan tentunya memerlukan layanan khusus dalam mengenyam pendidikan. Namun nyatanya persentase penduduk usia 5 tahun ke atas penyandang disabilitas yang masih sekolah hanya 5,48\%. Persentase tersebut jauh dari penduduk non-disabilitas yang mencapai 25,83\% (Jayani, 2019). Khususnya bagi penyandang tunanetra, karena berdasarkan data sensus penduduk tahun 2010 dari persentase penduduk umur $\geq 10$ tahun yang mengalami kesulitan penglihatan menduduki peringkat pertama yaitu 3,05\% atau sekitar 5.820 anak. Hal ini juga diperkuat dengan banyaknya penyandang disabilitas yang belum atau tidak pernah mengenyam pendidikan sama sekali mencapai 23,91\%, dan yang tidak bersekolah lagi sebesar 70,62\% (Admin, 2019). Hal ini dapat disebabkan sarana dan prasarana pendidikan bagi penyandang disabilitas khususnya penyandang tunanetra masih terbatas dan belum merata secara menyeluruh. Kurangnya sarana dan prasarana tersebut berimbas pada terhambatnya proses pembelajaran salah satunya pelajaran matematika bagi penyandang tunanetra.

Berdasarkan Alawiyah \& Hamad (2017) yang melakukan wawancara dengan Ketua Yayasan Mitra Netra, organisasi yang peduli dengan peningkatan kualitas hidup penyandang disabilitas tunanetra menyebutkan bahwa ketersediaan buku Braille berbahasa Indonesia masih sekitar 2.800 judul. Jumlah yang terbatas ini salah satunya dikarenakan buku Braille tidak efisien dan tidak praktis untuk dibawa. Hal ini tentu menghambat penyandang tunanetra yang ingin mendapatkan informasi dan pendidikan lebih luas layaknya orang yang berpenglihatan normal. Maka dari itu, untuk menunjang keberhasilan dalam belajar, selain materi ajar juga dibutuhkan bahan ajar baik berbentuk cetak atau elektronik.

Penulis beranggapan bahwa perlunya bahan ajar khusus bagi penyandang tunanetra yang efisien untuk mengembangkan kemampuan matematika. Penulis berinisiatif untuk merancang media pembelajaran matematika yang efisien dan fleksibel bagi penyandang tunanetra dengan membuat aplikasi android berbasis suara yang disimpan pada penyimpanan awan (cloud storage). Aplikasi tersebut akan diisi lantunan suara materi fondasi geometri atau lebih dikenal sebagai Geometri Euclid. Melalui bahan ajar berupa aplikasi berbasis suara tersebut diharapkan penyandang tunanetra dapat memperoleh bahan ajar yang efisien dan mutakhir sehingga mereka dapat melanjutkan ke pendidikan tinggi bahkan menjadi seorang matematikawan. Penggunaan media pembelajaran berbasis teknologi merupakan salah satu cara yang terbukti dapat membantu siswa atau peserta didik untuk meningkatkan kemampuan dan/atau membantu peserta didik dalam belajar (Maskar \& Endah, 2019). Selain itu, bahan ajar berbasis internet juga terbukti valid, efekti dan praktis, serta terbukti dapat signifikan meningkatkan pemahaman terhadap suatu materi (Maskar \& Dewi, 2020). Berdasarkan hasil penelitian yang dilakukan oleh Sánchez et al. (2005), pembelajaran matematika melalui audio dapat menjadi sumber kuat untuk meningkatkan memori dan pembelajaran matematika pada anak-anak tunanetra. Selanjutnya aplikasi yang dikembangkan akan diberi nama Euclidean Voice: Aplikasi Pembelajaran Geometri Euclid berbasis Android untuk Penyandang Tunanetra.

\section{METODE PENELITIAN}

Metode penelitian pada artikel ini disusun menggunakan teknik literatur review menggunakan beberapa sumber atau referensi yang relevan dengan media yang dikembangkan untuk mendapatkan hasil yang valid mengenai implementasi media Euclidean Voice pada siswa tunanetra. Literature review merupakan suatu langkah menuju tahap selanjutnya dalam suatu penyelesaian proses penelitian (Canwell \& Daily dalam Rahayu et al., 2019; Klutar Singh dalam Maskar \& Anderha, 2019).

Adapun tahapan penyusunan literature review pada penelitian ini diantaranya: 1) mendefinisikan kajian atau ruang lingkup topik yang akan direvieu, 2) mengidenfifikasi bahan referensi yang relevan dan berkualitas melalui google scholar, 3) memilih beberapa referensi dari google scholar dan mengelompokan filenya berdasarkan kriteria, 4) menyusun matriks sintesis dari artikel yang diperoleh, 5) menulis review, 6) 
Jurnal Ilmiah Matematika Realistik (JI-MR), Vol: 1, No: 2, 23-27

menyimpulkan dan mengaplikasikan hasil review (Denney \& Tewksbury, 2013; Prasetyo, 2017; Rahayu et al., 2019; Ramdhani et al., 2014).

Topik pada peneliitan ini mengenai pengembangan bahan ajar Geometri Euclid dengan menggunakan media aplikasi android dengan bantuan suara. Oleh karena itu kata kunci pencarian bahan referensi meliputi "media pembelajaran", "matematika", dan "tunanetra". Selanjutnya pencarian referensi menggunakan bantuan google scholar melalui tautan https://scholar.google.co.id/. Kemudian dilakuan seleksi atau pemilihan artikel dan disusun pada matriks sintesis untuk kemudian dibuat literature review dengan tujuan mengetahui hasil implementasi media euclidean voice pada siswa tunanetra.

Matriks sintesis pada penelitian ini disusun berdasarkan pengembangan dari beberapa referensi (Prasetyo, 2017; Rahayu et al., 2019) sehingga matriks yang dibuat akan berbentuk sebagai berikut:

Tabel 1. Template Matriks Sintesis Euclidean Voice

\begin{tabular}{|l|l|l|l|l|l|}
\hline $\begin{array}{l}\text { Penulis \& } \\
\text { Tahun }\end{array}$ & Judul & Desain & Sampel & Temuan & Kesamaan \\
\hline Sumber \#1 & & & & & \\
\hline Sumber \#2 & & & & & \\
\hline Sumber \#3 & & & & & \\
\hline Dst. & & & & & \\
\hline
\end{tabular}

\section{HASIL DAN PEMBAHASAN}

Secara umum hasil dan pembahasan pada artikel ini terbagi menjadi dua yaitu analisis terhadap media dan penggunaan suara pada aplikasi Euclidean Voice yang dikembangkan berdasarkan analisa literature review serta analisis terhadap pemahaman materi berdasarkan beberapa referensi yang dikumpulkan dan dianalisa mengenai efektifitas penggunaan media pada pemahaman matematika siswa tunanetara.

\section{Analisis Terhadap Media dan Penggunaan Suara}

Beberapa penelitian menemukan fakta menarik terkait dengan penggunaan media pembelajaran secara umum dan media berbasis suara untuk membantu siswa tunanetra dalam belajar, terutama dalam pembelajaran matematika. Beberapa media tersebut diantaranya audiobook, media audio characteristics of organism song education (chosen) dan alat peraga manipulatif. Ketiga media tersebut terbukti layak dan efektif diterapkan pada siswa tunanetra sebagai alat bantu proses pembelajaran matematika. Selain itu, media-media tersebut juga dapat meningkatkan ketertarikan siswa tunanetra dalam belajar matematika (Anwas, 2014; Hidayati \& Pribadi, 2014; Saksono, 2020).

Euclidean voice mempunyai spesifikasi yang serupa dan bahkan di atas dari beberapa media yang telah disebutkan sebelumnya. Euclidean voice dilengkapi oleh perintah dan pesan suara yang dikembangkan menggunakan bantuan dari teknologi text to speech dan speech to text milik Google, serta menggunakan bantuan Google Voice pada beberapa perintah atau pesan suara yang digunakan. Selain itu, Euclidean Voice juga menggunakan suara asli dari manusia utnuk penjelasan materi yang disampaikan. Hal teresebut bertujuan agar volume dan intonasi suara yang dihasilkan sesuai dengan kalimat yang digunakan sehingga dapat dipahami oleh pengguna serta tidak bermakna ganda. Berikut tampilan awal Aplikasi Euclidean Voice yang memuat pesan dan perintah suara melaui Google Voice.

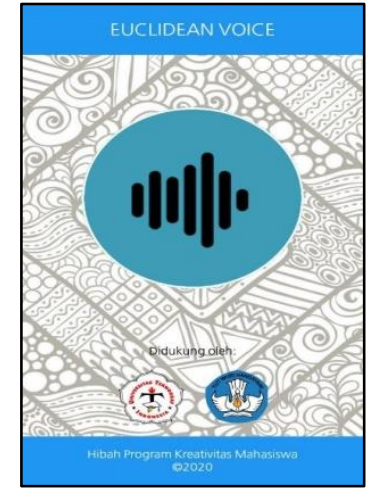

Gambar 1. Tampilan Awal Euclidean Voice 
Lebih jauh, aplikasi Euclidean Voice juga mengandalkan sentuhan atau ketukan sebagai salah satu perintah yang dapat digunakan oleh pengguna. Cara lainnya yang dapat digunakan oleh pengguna untuk mengguankan aplikasi tersebut yaitu dengan perintah suara akibat dari teknologi speech to text. Cara tersbut bertujuan agar pengguna yang merupakan tunanetra dapat menggunakan aplikasi tersebut dengan optimal walaupun tanpa melihat. Gambar 2 menunjukan tampilan aplikasi Euclidean Voice saat digunakan.

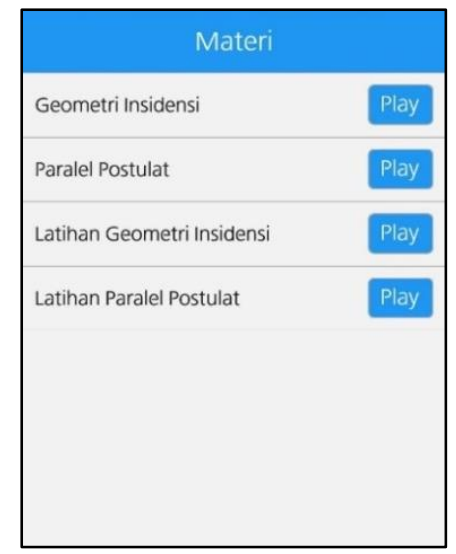

Gambar 2. Tampilan Isi Euclidean Voice

Berdasarkan informasi tersebut dan referensi yang telah dikumpulkan dan dianalisa sebelumnya, dapat ditarik kesimpulan bahwa aplikasi Euclidean Voice layak untuk digunakan atau diimplementasikan pada pengguna atau siswa tunanetra untuk dapat mempelajari materi Geometri Euclid. Selain itu, penggunaan Euclidean Voice juga akan efektif dalam meningkatkan ketertarikan siswa tunanetra untuk dapat mempelajari matematika lanjut, khsususnya bagi penyandang tunanetra yang memang menyenangi matematika dasar.

\section{Analisis Terhadap Pemahaman Materi}

Metode pembelajaran yang diberikan pada aplikasi Euclidean Voice ini bertujuan agar pengguna yang merupakan siswa tunanetra dapat memvisualkan materi yang diberikan melaui suara yang dapat diperintahkan oleh pesan suara juga. Siswa tunanetra dapat menyelesaikan permasalahan matematika dengan teknik mempresentasikan pengetahuan yang diterima melalui pesan suara menjadi bentuk visual (Kartika \& Mutmainah, 2019). Selain itu, beberapa penyandang tunanetra juga tidak dapat menggunakan bahasa braille. Oleh karena itu, penggunaan suara menjadi alternatif penting untuk menanggulangi permasalahan tersebut. Sebelumnya, siswa tunanetra yang tidak dapat menulis braille perlu mendatangkan guru khsusus pendamping (GKP) untuk membantu siswa tunanetra membacakan materi dan soal di buku. Namun karena tidak dapat mencatat, untuk mengulang materi tersebut, siswa tunanetra perlu selalu didampingi oleh GKP sehingga tidak efektif maupun efisien (Aulia \& Sopandi, 2019).

Siswa tunanetra sesungguhnya tidak berbeda dengan siswa normal lainnya, mereka dapat memahami soal, mengetahui materi yang dibahas, bahkan menyebutkan kembali data-data yang terdapat pada soal. Selain itu, siswa tunanetra juga dapat mengekspresikan jawaban atau solusi permasalahan matematika dengan baik dari soal yang diberikan melalui suara (Anggreini et al., 2017; Astuti, 2015). Selain itu, berdasarkan Maskar, dkk (2020) dan Saputra \& Febriyanto (2019), pembelajaran mandiri sesungguhnya dapat dilakukan dengan hasil sama dengan pembelajaran konvensional menggunakan guru dengan syarat ditunjang oleh media pembelajaran yang tepat dan berbasis teknologi. Fakta tersebut menunjukan bahwa aplikasi Euclidean Voice dimana soal latihan pada aplikasi tersebut dibacakan melalui pesan suara dan solusi akan diekspresikan oleh siswa langsung pada pendamping atau guru akan berjalan efektif dan efisien. Selain itu, penggunaan suara yang disimpan pada aplikasi juga mengefektifkan waktu dan mengefisiensi biaya yang dikeluarkan untuk mendatangkan GKP.

\section{SIMPULAN}

Aplikasi Eclidean Voice merupakan aplikasi yang dikembangkan dengan fasilitas penggunaan suara baik dari instruksi maupun perintah dari aplikasi maupun untuk menjalankan aplikasi. Aplikasi tersebut juga memungkinkan pengguna yang sasarannya siswa tunanetra untuk dapat menjalankan aplikasi secara keseluruhan 
Jurnal Ilmiah Matematika Realistik (JI-MR), Vol: 1, No: 2, 23-27

dengan menggunakan perintah suara serta bantuan ketukan sebagai alternatif lainnya. Materi yang dilantukan oleh Euclidean Voice juga dapat di jeda, dianjutkan ketika posisi jeda, maupun dihentikan oleh pengguna dengan perintah suara sehingga pengguna dapat belajar materi Geometri Euclid dengan mudah. Selain itu, pengguna yang tidak dapat menulis braille dapat memanfaatkan aplikasi ini untuk mengulang materi sampai pengguna memahami materi yang disampaikan. Lebih jauh, pengguna juga dapat mengecek pemahamannya melalui menu latihan yang disediakan.

Aplikasi Euclidean voice dapat bekerja optimal dan efektif digunakan sebagai media pembelajaran siswa tunanetra untuk mempelajari matematika lanjut, dalam hal ini Geometri Euclid. Kesimpulan tersebut didapatkan berdasarkan asosiasi fasilitas pada aplikasi dengan beberapa referensi yang relevan. Referensi tersebut telah teruji untuk mengefektifkan proses pembelajaran pada siswa tunanetra serta mampu meningkatkan pemahaman dan ketertarikan siswa tunanetra dalam pelajaran matematika.

Aplikasi ini telah terbukti dapat diimplementasikan pada pengguna, sehingga disarankan bagi siswa, pengajar, maupun institusi pendidikan yang menaungi siswa tunanetra untuk dapat memanfaatkan aplikasi Euclidean Voice ini untuk dapat membantu dalam memepelajari matematika tingkat lanjut. Selain itu, diharapkan dengan berkembangnya media-media yang mutakhir dengan memamnfaatkan teknologi, suatu saat terdapat pakar matematika dari kalangan tunanetra.

\section{REFERENSI}

Admin. (2002). Undang Undang Nomor 20 Tahun 2003 tentang Sistem Pendidikan Nasional. www.dpr.go.id Admin. (2019). Situasi Penyandang Disabilitas Kementerian Kesehatan. www.pusdatin.kemkes.go.id

Alawiyah, T., \& Hamad, I. (2017). Penerimaan Informasi Melalui Digital Talking Book oleh Siswa Tunanetra. 21, 44-58.

Anggreini, D. A., Setiawan, T. B., \& Oktavianingtyas, E. (2017). Representasi Matematis Siswa Tunanetra dalam Memahami Konsep Segitiga Berdasarkan Teori Van Hiele. Kadikma, 8(2), 144-154.

Anwas, O. M. (2014). Audiobook: Media Pembelajaran Masyarakat Modern. Jurnal Teknodik, 18(1), 54-62.

Astuti, V. . (2015). Identifikasi Proses Berpikir Berdasarkan Asimilasi dan Akomodasi dalam Memecahkan Masalah Geometri pada Siswa SMP Penyandang Tunanetra. Prosiding Seminar Nasional Matematika Dan Pendidikan Matematika, 255-265.

Aulia, W. P., \& Sopandi, A. A. (2019). Cara Belajar Siswa Tunanetra dalam Pembelajaran Matematika Kelas X di SMK Negeri 7 Padang. 7, 155-160.

Denney, A. S., \& Tewksbury, R. (2013). How to Write a Literature Review Paper. Journal of Criminal Justice Education, 24(2), 218-234. https://doi.org/http://dx.doi.org/10.1080/10511253.2012.730617

Hidayati, F., \& Pribadi, T. A. (2014). Pengembangan Media Audio Characteristics of Organism Song Education (Chosen) Pada Pembelajaran IPA Biologi di SMPLB-A (Tunanetra). Unnes Journal of Biology Education, 3(2), 156-163. http://journal.unnes.ac.id/sju/index.php/ujbe

Jayani, D. H. (2019). Pada 2018, Hanya 5,48\% Penyandang Disabilitas yang Masih Sekolah. www.databoks.katadata.co.id

Kartika, H., \& Mutmainah, S. (2019). Representasi Pengetahuan Secara Visual: Kajian Terhadap Orang Tunanetra dan Pemecahan Masalah Matematika Soal Cerita. Jurnal Kajian Pembelajaran Matematika, 3(2), 58-66. http://journal2.um.ac.id/index.php/jkpm

Maskar, S. \& Wulantina, E. (2019). Persepsi Peserta Didik terhadap Metode Blended Learning dengan Google Classroom. Inomatika: Inovasi Matematika. 1(2). 110-121.

Maskar, S. \& Dewi, P.S. (2020). Praktikalitas dan Efektifitas Bahan Ajar Kalkulus Berbasis Daring Berbantuan Geogebra. Jurnal Cendekia (Jurnal Pendidikan Matematika). 4(2), 888-899.

Maskar, S, dkk. (2020). Online Learning \& Blended Learning: Perbandingan Hasil Belajar Metode Daring Penuh dan Terpadu. 9(2), 154-166.

Maskar, S. \& Anderha, R.R. (2019). Pembelajaran Transformasi Geometri dengan Pendekatan Motif Kain Tapis Lampung. Mathema: Jurnal Pendidikan Matematika. 1(1), 40-47

Prasetyo, W. (2017). Literature Review: Stres Perawat Di Ruang Instalasi Gawat Darurat. Jurnal Ners Lentera, 5(1), $43-55$.

Rahayu, T., Syafril, S., Wekke, I. S., \& Erlinda, R. (2019). Teknik Menulis Review Literatur Dalam Sebuah Artikel Ilmiah. September. https://doi.org/10.31227/osf.io/z6m2y

Ramdhani, A., Ramdhani, M. A., \& Amin, A. S. (2014). Writing a Literature Review Research Paper: A step-by-step approach. The Journal of Applied Behavioral Science, 3(1), 47-56.

Saksono, D. Y. (2020). Meningkatkan Kemampuan Koneksi Matematis Siswa Tunanetra Dengan Alat Peraga Manipulatif. Delta: Jurnal Ilmiah Pendidikan Matematika, 8(1), 95. https://doi.org/10.31941/delta.v8i1.967

Sánchez, J., Flores, H., \& Sánchez, J. (2005). AudioMath: Blind children learning mathematics through audio. International Journal on Disability and Human Development, 4(4), 311-316. https://doi.org/10.1515/IJDHD.2005.4.4.311

Saputra, V.H. \& Febriyanto, E. (2019). Media Pembelajaran Berbasis Multimedia untuk Anak Tuna Grahita. Jurnal Ilmiah Matematika Realistik.1(1), 15-23 